\title{
Öğretmenlerin Eğitim Denetmenlerine İlişsin Metaforik Algıları
}

\section{Metaphorical Perceptions of Teachers on Education Supervisors}

\begin{abstract}
Osman Vaiz*
Nesrin M. Bahçelerli***

Akış Vaiz ${ }^{* * *}$

$\ddot{\mathbf{O} z}$

Metafor, bir kavramın başka bir kavram veya olgu ile açıklanması ve algıda seçicilik yaratılmasıdır. Bu araştırmanın amacı, Kıbrıs’ta Kıbrıslı Türk ve Kıbrıslı Rum ilköğretim öğretmenlerinin eğitim denetmenlerine ilişkin algılarını metafor aracılığıyla ortaya çıkarmaktır. Araştırmaya, 21 Kıbrıslı Rum ve 32 Kıbrıslı Türk öğretmen katılmıştır. Katılımcılardan,metafor kavramı ile bir kavramın, olgu veya olayın başka bir kavram, olgu veya olaya benzetilerek açıklanması istenmiştir. Araştırmanın nitel boyutunda örneklem alınırken amaçlı örneklem yöntemine başvurulmuştur. Araştırma amaçlı örnekleme yöntemlerinden biri olan maksimum çeşitlilik örneklemesi kullanılmıştır. Araştırmanın bulgularına göre; her iki toplumda da olumlu metaforların daha fazla olduğu saptanmıştır.
\end{abstract}

Anahtar sözcükler: Denetmen, Öğretmen, Metafor, Kıbrıs

\begin{abstract}
Metaphor is the explication of a concept by another term or phenomenon and the creation of selectivity in perception. The aim of this research is to reveal the perceptions of Turkish Cypriot and Greek Cypriot primary school teachers about the education supervisors through the metaphors in Cyprus. the research population is defined as the teachers who work in primary education institutions in the North and South of Cyprus in the academic year 2016-2017. The research was applied 32 educators from Turkish Cypriots, and 21 educators from Greek Cypriots. Qualitative sampling of the study was applied to the purposeful sampling method. In the thesis, sampling of maximum diversity, which is one of the purpose sampling methods, is used.According to the findings of the research; positive metaphors were found to be more frequent in both communities.
\end{abstract}

Keywords: Supervisor, Teacher, Metaphor, Cyprus

\footnotetext{
* Dr., Uluslarası Kıbrıs Üniversitesi, Eğitim Bilimleri Fakültesi

${ }^{* *}$ Doç.Dr., Yakın Doğu Üniversitesi, Turizm ve Otel İşletmeciliği Yüksekokulu

${ }^{* * *}$ Uzman
} 


\section{Giriş}

Öğrenimin daha etkili olmasını sağlamak amacı ile denetim hem okul işleyişini hem de öğretim sürecini doğrudan etkileyen şekilde düzene sokmaktadır. Öğretimde denetim, okul içerisinde eğitim ve öğretim faaliyetlerinin gelişitirilmesini ve sürdürülmesini amaçlamaktadır. Ben Haris tarafından tanımlanan denetim, yönetim açısından davranış analizi, görevleri, süreci ve becerileri bakımından, denetimsel davranış açısından uygulanır (Aydın, 1998).

Denetimin temel amacı, işleyişi gözemleyerek olması gereken ve hedeflenenle şu anki işleyişi karşılaştırma yöntemidir. Öyle ki denetim önceden belirlenen kriter ve standartlara uygunluğun ortaya çıkarılışı olarak tanımlanmaktadır. Klasik yaklaşımda denetimin öncelikli görevi, hataların engellenmesi olarak değerlendirilmektedir. Diğer bir yaklaşımda ise denetim, sadece meslek olarak değil yenilikçiliğin, çağdaş olmanın, toplumsal açıdan kalkınmanın ve feraha ulaşmanın bir parçası, ülkenin gelişimine katkı koyan, girişimciliği destekleyen öğelerin içiçe geçmesiyle ortaya çıkan bir kavram ve olgu olarak tanımlanmaktadır (Köse, 2007).

Denetmenin başlıca amaçları arasında öğretmenlere ihtiyaç duydukları destek ve yardımı sunmak, eğitim ve öğretim sürecinde ihtiyaç duydukları materyal ve teknoloji sağlamada yardımcı olmak yer almaktadır (Wanzare ve Costa, 2000).

Metafor basit olarak dolaylı anlatım şeklinde tanımlanmaktadır .Yunanca metapherein kelimesinden türeyerek"Bir yerden bir yere taşımak" anlamına gelmektedir (Karaırmak ve Güloğlu, 2012). Saban, Koçbeker ve Saban (2006) yaptıkları çalışmada metaforu, bireyin soyut bir olguyu anlamada ve açıklamda kullandığı zihinsel bir araç olarak tanımlamaktadırlar. 1980’de ilk kez Lakoff ve Johnson yaptıkları çalışma da metafor geliştirilmişlerdir (Beşkardeş, 2007). Literatürde metaforun söz figürü olmasının yanı sıra aynı zamanda düşünce figürü olarak tanımlandığı görülmektedir. Metafor, kişinin kendi dünyasında ki çözümleme, oluşturma ve yaratmaları doğrultusunda etkili zihinsel şekillendirme yöntemidir.

Metaforlar genellikle bireyin gerçek yaşantısını ve tecrübelerini nasıl yorumladığını ortaya çıkarma amacıyla ku daha çok gerçek ve yaşantının, kişide nasıl yorumlandığının anlaşılması için kullanılmaktadır (Güven ve Güven, 2009). Geçit ve Gencer, (2011) araştırmalarında bireyin hem kendi duygu ve düşüncesini hem de karşısındaki bireylerin duygu ve düşüncelerini tanımlarken sık sık metafor kullanıldığını vurgulamaktadırlar.

Metaforlar, bireyin hayata bakış açılarının ve algılarının ortaya çıkarılmasında önemli bir olgudur (Şahin ve Baturay, 2013). Silman ve Şimşek (2006) metaforların sosyal olguları 
anlamada hem betimleme hem de karşılaştırma aracı olarak kullanılabileceklerini vurgulamaktadırlar.Metaforlar bir çok biçimde tanımlanabilmektedir. Örneğin; soyut, somut,canlı, cansız, olumlu ve olumsuz gibi. Tanımlanması zor olay ve durumların daha kolay anlaşılmasını sağlayan metaforlar aynı zamanda bilgi toplama ve irdeleme aracıdır (Semerci, 2007).

$\mathrm{Bu}$ araştırmanın amacı iki toplumlu Kıbrıs’ta, Kıbrıslı Rum ve Kıbrıslı Türk öğretmenlerin eğitim denetmenlerine ilişkin metaforik algılarını ortaya çıkarmaktır.

\section{Yöntem}

Araştırmanın nitel boyutunda örneklem alınırken amaçlı örneklem yöntemine başvurulmuştur. Amaçlı örneklem, seçkisiz olmayan örnekleme yöntemlerinden biridir. Ayrıntılı ve derinlemesine bir çalışma gerçekleştirebilmek amacıyla zengin veri elde edebilecek kişilere ya da dokümanlara ulaşılır. Bu kişilerden/dokümanlardan araştırma soruları temelinde veri elde edilir (Bogdan\&Biklen, 2006; Glesne, 2011). Araştırmada, amaçlı örnekleme yöntemlerinden biri olan maksimum çeşitlilik örneklemesi kullanılmıştır. Maksimum çeşitlilik örneklemesi seçilerek farklı bakış açılarından yararlanmak ve araştırma bulgularında zengin bir veri setine ulaşmak amaçlanmıştır. Araştırmanın evrenini 2016-2017 eğitim öğretim yılında Kıbrıs'ın kuzeyinde ve güneyinde ilköğretim kurumlarında görev yapan öğretmenleri oluşturmaktadır. Araştırmaya, 21 Kıbrıslı Rum ve 32 Kıbrıslı Türk öğretmen katılmıştır. Katılımcılardan, metafor kavramı ile bir kavramın, olgu veya olayın başka bir kavram, olgu veya olaya benzetilerek açıklanması istenmiştir. Verilerin değerlendirilmesi sürecinde katılımcılar tarafindan üretilen metaforlar nedenleri ile birlikte incelenerek olumlu ve olumsuz olmak üzere iki kategoride toplanmıştır. Metaforların kategorilendirilmesinde önceki araştırmalar incelenmiş ve uzman görüşü alınmıştır.

\section{Bulgular ve yorum}

"Denetmeni, canlı ya da cansız bir şeye benzetecek olsaydını neye benzetirdiniz?" sorusuna ilişkin Kıbrıslı Türk katılımcılardan elde edilen bulgular Tablo 3 ve 4'te sunulmuştur.

Tablo 1. Kıbrıslı Türk katılımcıların denetmeni benzettikleri metafor

\begin{tabular}{lll}
\hline Metafor & Olumlu & Olumsuz \\
\hline
\end{tabular}




\begin{tabular}{|c|c|c|c|}
\hline \multirow{14}{*}{ Canlı } & \multirow{7}{*}{ İnsan } & & \multirow{7}{*}{$\begin{array}{l}\text { Çekinilecek biri } \\
\text { Dedektif }\end{array}$} \\
\hline & & Somates & \\
\hline & & Gemı kaptanı & \\
\hline & & Anne-baba & \\
\hline & & Denetmen & \\
\hline & & İnsan (3) & \\
\hline & & Organizma & \\
\hline & \multirow{5}{*}{ Hayvan } & & Eşek \\
\hline & & & Koyun \\
\hline & & & Kirpi (Dikenlerini her \\
\hline & & & an batıracakmış gibi) \\
\hline & & & Y1lan (sinsi) \\
\hline & \multirow{2}{*}{ Bitki } & & Kaktüs \\
\hline & & & Isırgan otu \\
\hline \multirow{11}{*}{ Cansız } & \multirow{11}{*}{ Madde } & Zincir & Robot \\
\hline & & Bağlantı kablosu & (hakimin \\
\hline & & Meşale & k1rdiğ1) \\
\hline & & Ayna & Tokmak \\
\hline & & Trafik lambası & vurduğu) \\
\hline & & Güneş (2) & \multirow[t]{6}{*}{ Siyasi parti (ctp) } \\
\hline & & Deniz feneri & \\
\hline & & Bilgi küpü & \\
\hline & & Pusula & \\
\hline & & El feneri & \\
\hline & & Kamera & \\
\hline
\end{tabular}

"Denetmeni, canlı ya da cansı bir şeye benzetecek olsaydını neye benzetirdiniz?" sorusuna ilişkin araştırmanın Kıbrıslı Türk katılımcıları toplam 32 görüş ortaya koymuştur. $\mathrm{Bu}$ görüşlerden "Canlı, insan ve olumlu" kategorisinde Sokrates, gemi kaptanı, anne-baba, denetmen, insan (3) ve organizma olarak belirtilmiştir. "Canlı, insan ve olumsuz" kategorisinde çekinilecek biri ve dedektif olarak belirtilmiştir. "Canlı, hayvan ve olumsuz" kategorisinde eşek, koyun, kirpi (dikenlerini her an batıracakmış gibi) ve yılan (sinsi)olarak belirtilmiştir. “Canlı, bitki ve olumsuz” kategorisinde kaktüs ve 1sırgan otuolarak belirtilmiştir. “Canlı hayvan olumlu” ve “Canlı bitki olumlu” kategorilerinde herhangi bir görüş belirtilmemiştir. "Cansız madde olumlu” kategorisindezincir, bağlantı kablosu, meşale, ayna, trafik lambası, güneş (2), deniz feneri, bilgi küpü, pusula, el feneri, kamera olarak belirtilmiştir. 
"Cansız madde olumsuz" kategorisinderobot, kalem (hakimin kırdığı), tokmak (hakimin vurduğu), siyasi parti (CTP) olarak belirtilmiştir.

Tablo 2. Kıbrıslı Türk katılımcıların denetmeni benzettikleri metaforun olumlu-olumsuz dağılımı

\begin{tabular}{|c|c|}
\hline TEMA & Kıbrislı Türk (f) \\
\hline Olumlu & 20 \\
\hline Olumsuz & 12 \\
\hline & 32 \\
\hline
\end{tabular}

“Denetmeni, canlt ya da cansız bir şeye benzetecek olsaydını neye benzetirdiniz?" sorusuna ilişkinaraştırmanın Kıbrıslı Türk katılımcılarının ortaya koyduğu toplam 32 görüşün 20'si “olumlu” ve 12'si “olumsuz” şekilde kategorize edilmiştir. “Olumlu”görüşler Sokrates, gemi kaptanı, anne-baba, denetmen, insan (3), organizma, zincir, bağlantı kablosu, meşale (2), ayna, trafik lambası, güneş (2), deniz feneri, bilgi küpü, pusula ve el feneri şeklindedir.

“Olumsuz"görüşler çekinilecek biri, dedektif, eşek, koyun, kirpi (dikenleriniher an batıracakmış gibi), yılan (sinsi), kaktüs, 1sırgan otu, robot, kalem (hakimin kırdığı), tokmak (hakimin vurduğu) ve siyasi parti (ctp) şeklindedir.

"Denetmeni, canlı ya da cansız bir şeye benzetecek olsaydını neye benzetirdiniz?" sorusuna ilişkin Kıbrıslı Türk katılımcılardan elde edilen bulgular Tablo 3 ve 4'de sunulmuştur.

Tablo 3. Kıbrıslı Rum katılımcıların denetmeni benzettikleri metafor

\begin{tabular}{llll}
\hline Metafor & Olumlu & Olumsuz \\
\hline & & Dost & Dedektif \\
& Insan & Lider & Sikıcı \\
& & Baş & Polis \\
\cline { 2 - 4 } Canlı & Hayvan & Rehber & \\
\cline { 2 - 4 } & & Aslan &
\end{tabular}

Bitki 


\begin{tabular}{|c|c|c|c|}
\hline & & Meşale & İğne \\
\hline & & Köprü & Keser \\
\hline & & Kablo & Testere \\
\hline & & Sözlük & \\
\hline \multirow[t]{5}{*}{ Cansız } & Madde & Google & \\
\hline & & Harita & \\
\hline & & Pinar & \\
\hline & & (Kaynak) & \\
\hline & & Bilgisayar & \\
\hline
\end{tabular}

"Denetmeni, canlı ya da cansız bir şeye benzetecek olsaydını neye benzetirdiniz?" sorusuna ilişkinaraştırmanın Kıbrıslı Rum katılımcıları toplam 19 görüş ortaya koymuştur. $\mathrm{Bu}$ görüşlerden "canlı, insan ve olumlu" kategorisinde dost, lider, baş, rehber olarak belirtilmiştir.“canlı, insan ve olumsuz" kategorisinde dedektif, sıkıcı, polis olarak belirtilmiştir. "canlı, hayvan ve olumlu” kategorisinde aslan olarak belirtilmiştir. "canlı, bitki ve olumsuz" kategorisinde kaktüs ve isırgan otu olarak belirtilmiştir. "canlı hayvan olumsuz" ve “canlı bitki olumlu ve olumsuz" kategorilerinde herhangi bir görüş belirtilmemiştir. “Cansız madde olumlu” kategorisindemeşale, köprü, kablo, sözlük, Google, harita, pınar (kaynak), bilgisayar olarak belirtilmiştir. “Cansız madde olumsuz” kategorisindeiğne, keser, testere olarak belirtilmiştir.

Tablo 4. Kıbrıslı Türk katılımcıların denetmeni benzettikleri metaforun olumlu-olumsuz dağılımı

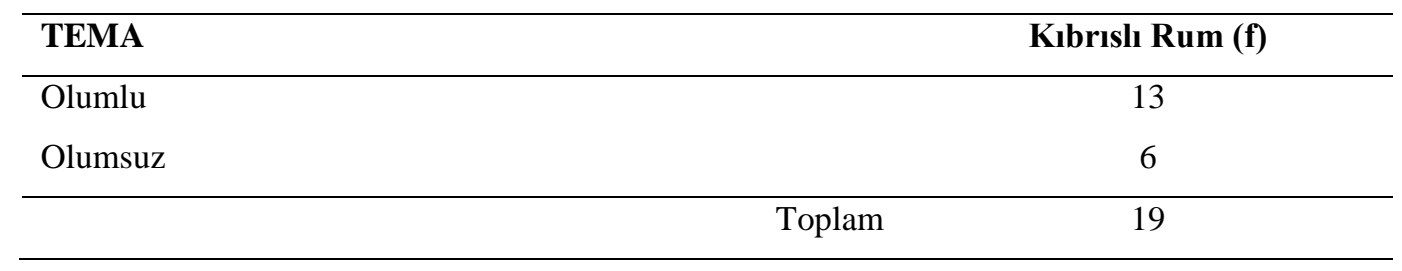

"Denetmeni, canlı ya da cansız bir şeye benzetecek olsaydını neye benzetirdiniz?" sorusuna ilişkinaraştırmanın Kıbrıslı Rum katılımcılarının ortaya koyduğu toplam 19 görüşün 13’ü “olumlu” ve 6's1 “olumsuz” şekilde kategorize edilmiştir. “Olumlu”görüşler dost, lider, baş, rehber, aslan, meşale, köprü, kablo, sözlük, Google, harita, pınar (kaynak), bilgisayarşeklindedir. “Olumsuz” görüşler dedektif, sıkıcı, polis, iğne, keser, testere şeklindedir.

Eski "denetleme" yöntemlerine ve denetmen özelliklerine bakıldığ $\breve{1}_{1}$ zaman, denetmenlerin öğretmenler tarafından pek hoşlanılan kişiler olmadığı yapılan araştırmalarda da 
sıkça vurgulanmıştır (Yaman, 2009; Şahin, Elçiçek ve Tösten, 2013). Günümüzdeki çağdaş yönetim anlayışlarında her ne kadar denetleme işlevinin ve denetmen rolünün değişiminden söz edilse de öğretmenlerin gözünde denetmenlerin olumsuz bir izlenim bıraktıkları gerçeği hala daha kendini göstermektedir. Bu bağlamda katılımcı öğretmenlere denetmenleri benzetecekleri bir metafor kavramı sorulduğumuz zaman Kıbrıslı Türklerin yaklaşık olarak yüzde kırkının; Kıbrıslı rumların ise yaklaşık olarak yüzde otuzunun olumsuz metafor kullanmış olmaları bu durumu destekler niteliktedir. Her iki toplumda da katılımcılar tarafından en çok kullanılan olumsuz metafor olarak ise "dedektif” ifadesi göze çarpmaktadır. Bu olumsuz metaforlar yanında özellikle yıl olarak mesleğe daha yeni başlayan ve kıdemi çok fazla olmayan öğretmenler, her iki toplumda da denetmenler için olumlu metaforlar kullanmışlar ve denetmenleri "dost, anne-baba, lider, google, meşale, bağlantı kablosu" gibi kavramlarla eşlemişlerdir. Kuşkusuzdur ki, her iki toplumda da araştırmalara katılan öğretmenlerin denetmenlerle ilgili kullandıkları metaforlarda olumlu ve olumsuz ifadelerin bulunması, günümüzde mevcut olan denetmenlerin özellikleri ile yakından ilişkilidir. Bu durumda, elde edilen metaforlar aslında bizi mevcut olan denetmenlerin olumlu ve olumsuz yönlerini sorgulama ve mevcut denetleme sistemindeki sorunları tartışmaya da yönlendirmektedir. $\mathrm{Bu}$ konu ile ilgili öğretmenlere yöneltilen sorulara verilen cevaplara bakıldığı zaman, Kıbrıslı Türk ve Kıbrıslı Rum öğretmenlerden denetmenlerin "kişilik ve tutumlarının olumlu yönde, liderlik ve rehberlik yapabilme becerilerinin" de var olduğunu savunanlar olmuştur. Bu olumlu özelliklerin yanında, öğretmenlerin gözünde denetmenlerden kaynaklanan sorunlar da mevcuttur.

\section{Sonuç}

Araştırmaya katılan Kıbrıslı Türk ve Rum katılımcılar denetmeni benzettikleri metaforun olumlu ve olumsuz olma durumuna göre benzer yapılar ortaya koymuşturlar. Her iki toplumda da olumlu metaforların bilgili, yol gösterici, kılavuz kavramlarıyla bağdaştı̆̆ı görülmüştür. Olumsuz metaforların ise denetimde yetersiz olma, denetlemeni hata aramakla bağdaştırma gibi kavramlarla bağdaştırıldığı göze çarpmaktadır. Bu bağlamda denetmenlerin eksik olan bilişsel, duyuşsal ve motor becerilerinin kazandırılmasına yönelik eğitimlerin düzenlenmesi önerilebilir.

\section{Kaynaklar}

Aydın, A. (1998). Eğitim fakültelerinin yeniden yapılandırılması ve öğretmen yetiştirme sorunu. Kuram ve Uygulamada Ĕ̈itim Yönetimi Dergisi, 4(3), 275- 286. 
Beşkardeş, S. (2007). Üstün zekâlı ve özel yetenekli öğrencilerin yabancı dil (İngilizce) öğretiminde metafor sisteminin uygulanması (Yayınlanmamış yüksek lisans tezi). Afyon Kocatepe Üniversitesi, Afyon.

Bogdan, R. C. \&Biklen, S. K. (2006). Qualitativ eresearch for education: An introduction to theory and methods, (5th edition). Boston: Allyn\& Bacon.

Geçit, Y. ve Gençer, G. (2011). Sınıf öğretmenliği 1. sınıf öğrencilerinin coğrafya algılarının metafor yoluyla belirlenmesi (Rize Üniversitesi Örneği). Marmara Coğrafya Dergisi, 23, 1-19.

Glesne, C. (2011). Becoming qualitative researchers: An introduction, (4th edition). Boston, MA: Pearson.

Güven, B. ve Güven, S. (2009). İlköğretim öğrencilerinin sosyal bilgiler dersinde metafor oluşturma becerilerine ilişkin nicel bir inceleme. Kastamonu Eğitim Fakültesi Dergisi, 17 (2), 503-512.

Karaırmak, Ö. ve Güloğlu, B. (2012). Metafor: Danışan ve psikolojik danışman arasındaki köprü, Türk Psikolojik Danışma ve Rehberlik Dergisi, 4 (37), 122-135.

Köse, H. Ö. (2007). Dünyada ve Türkiye'de Yüksek Denetim, 2. Baskı, . Ankara: T.C. Sayıştay 145 Yıl Yayınları.

Saban, A.,Koçbekir, B. N. ve Saban, A. (2006). Öğretmen adaylarının öğretmen kavramına ilişkin algılarının metafor analizi yoluyla incelenmesi. Kuram ve Uygulamada Eğitim Bilimleri, 6 (2) 461-522.

Semerci, Ç. (2007). Program geliştirme kavramına ilişkin metaforlarla yeni ilköğretim programlarına farklı bir bakış. Cumhuriyet Üniversitesi Sosyal Bilimler Dergisi, 31 (2), 125-140.

Silman, F., \& Şimşek, H. (2006). Türkiye ve Amerika Birleşik Devletleri okulları ve merkezi eğitim kurumlarına mecazlar yoluyla bir bakış. Eğitim Araştırmaları, 6(23), 177-187

Şahin, Ş. ve Baturay, M. H. (2013). Ortaöğretim öğrencilerinin internet kavramına ilişkin algılarının değerlendirilmesi: bir metafor analizi çalışması, Kastamonu Eğitim Dergisi, 1, 177-192

Şahin, S, Elçiçek, Z.,\&Tösten, R. (2013). Türk eğitim sisteminde teftişin tarihsel gelişimi ve bu gelişim süreci içerisindeki sorunlar. International Journal of SocialScience, 6(5) , 1105-1126.

Wanzare, Z. andCosta, J. L. (2000). Supervision and staff development: Overview of the literature. National Association of Secondary School Principals. NASSP Buletin: Oct. 2000. 84, 618, ProQuest Education Journals, 47-54.

Yaman, E. (2009). Müfettişlerin rehberlik rollerini rehber öğretmenler değerlendiriyor. International Online Journal of Educational Sciences, 1 (1), 106-123. 